Division of Hospital Medicine Northwestern University Feinberg School of Medicine, Chicago, IL, USA

2 Division of General Internal Medicine and Geriatrics, Northwestern University Feinberg School of Medicine, Chicago, IL, USA

3 Division of Pulmonary and Critical Care Medicine, Northwestern University Feinberg School of Medicine, Chicago, IL, USA

Correspondence to: J A Linder jlinder@northwestern.edu

Cite this as: BMJ2021;373:n1147 http://dx.doi.org/10.1136/bmj.n1147 Published: 07 May 2021

\section{Management of severe covid-19: progress and promise}

\section{We have learnt so much but there is lots more to learn}

\author{
Cheryl K Lee, ${ }^{1}$ Jeffrey A Linder, ${ }^{2}$ Khalilah L Gates ${ }^{3}$
}

Management of SARS-CoV-2 infection continues to evolve. For patients requiring hospital treatment, mortality can be high (up to $20 \%$ ) but has decreased over the course of the pandemic. Death rates depend on many factors, including age, gender, ethnicity, comorbidities, region, and the community prevalence of covid-19. ${ }^{1-4}$

Current therapeutic approaches are largely focused on one of the two phases of SARS-CoV-2 infection. The initial phase is marked by viral replication followed by a second phase associated with immune dysregulation, worsening respiratory symptoms, sepsis, organ dysfunction, and higher mortality.

Evidence does not support the use of many proposed therapies, including vitamins $\mathrm{C}$ and $\mathrm{D}$, zinc, lopinavir-ritonavir, colchicine, interferons, fluvoxamine, ivermectin, and convalescent plasma..$^{-9}$ Monoclonal antibodies against the SARS-CoV-2 spike protein are a promising therapy for mild-to-moderate illness in patients outside hospital. ${ }^{10}$

Glucocorticoids are the only medication known to decrease mortality in patients admitted to hospital with covid-19. The Recovery study found that dexamethasone $6 \mathrm{mg}$ daily for 10 days (or until discharge if earlier) decreased mortality in patients with hypoxaemia, especially those requiring mechanical ventilation. ${ }^{11}$ There was no difference in mortality-and a suggestion of increased mortality-in patients without hypoxaemia. Subsequent meta-analyses confirmed glucocorticoids' benefits in critically ill patients. ${ }^{12} 13$

\section{Beyond glucocorticoids}

Remdesivir, an intravenously administered nucleoside analogue, shortened time to recovery by five days among hospital patients in the ACTT-1 trial. ${ }^{14}$ The largest effects were seen in patients treated within 10 days of first symptoms and those needing supplemental oxygen but not advanced support such as high flow nasal cannula or mechanical ventilation. The Solidarity trial, however, reported no mortality benefit over placebo in hospital patients, ${ }^{15}$ and recommendations vary. The US National Institutes of Health and Infectious Diseases Society of America, for example, conditionally recommend remdesivir for hypoxaemic patients whereas the World Health Organization recommends against, particularly when costs and feasibility of use globally are considered. ${ }^{16-18}$

Other promising treatments include the interleukin-6 receptor antagonist tocilizumab and the Janus kinase inhibitor baricitinib. Evidence from randomised controlled trials of IL-6 receptor antagonists is conflicting. In Remap-Cap, patients receiving tocilizumab required less organ support and had improved survival, but other trials failed to replicate these findings. ${ }^{19}$ In the Recovery trial, tocilizumab increased survival only when given with a corticosteroid, so the observed benefit may be due to steroids alone. ${ }^{20}$ Further evidence on IL- 6 receptor antagonists is required, and likely to follow.

In a trial of baricitinib plus remdesivir, a subset of patients requiring non-invasive ventilation or high flow oxygen recovered eight days quicker than those given remdesivir alone. ${ }^{21}$ However, this advantage disappeared in those also given glucocorticoids. An ongoing trial is comparing baricitinib with dexamethasone in patients given remdesivir. Trials of other immunomodulators are also underway.

Antibiotic overuse remains a problem in the treatment of covid-19. Early in the pandemic, half of all admitted patients received antibiotics. ${ }^{22}$ However, less than $5 \%$ of patients have bacterial co-infection at presentation, although the incidence of secondary bacterial infection is somewhat higher at $14 \% .{ }^{23}$ Guidelines recommend against empirical antibiotics for hospital patients with covid-19 unless there is strong evidence of bacterial infection. ${ }^{24}$ For those who are critically ill, however, it is reasonable to prescribe antibiotics until bacterial infection can be ruled out. Biomarkers such as procalcitonin can be raised in patients with covid-19 and should not be used in isolation to guide use of antibiotics. ${ }^{25}$

Covid-19 is associated with increased risk of thrombosis, both large thrombi and microthrombi in various organs. ${ }^{26}$ Thromboprophylaxis is recommended within 24 hours of admission (in the absence of contraindications), as one retrospective study suggested a survival benefit. ${ }^{27}$ In critically ill patients, evidence supports prophylactic doses of anticoagulants for adults without frank thromboembolism, but trials of intermediate or therapeutic intensity treatment have been halted because of lack of benefit. ${ }^{28}$ Similarly, no high quality evidence supports therapeutic dose anticoagulation in hospital patients who are not critically ill.

\section{Non-drug management}

The importance of intensive nursing and supportive care cannot be overstated. Hospital mortality in the United States fell from $22 \%$ in March 2020 to $12 \%$ in May, before widespread use of drugs such as dexamethasone. ${ }^{29}$ Conservative fluid management, adequate supplemental oxygen, proning, and lung protective ventilation have been essential in improving outcomes. Early intubation for those requiring more than $6 \mathrm{~L} / \mathrm{min}$ of oxygen is no longer recommended, as patients can be supported more 
effectively and safely with high flow nasal cannulas and non-invasive ventilation. ${ }^{30}$

Effective communication is also critical. Patients with covid-19 are managed by a variety of health professionals, including nurses, physiotherapists, and physician specialists in hospital medicine, infectious diseases, pulmonary medicine, critical care, and palliative care. Each team member should aim for honest, straightforward conversations with patients, families, and caregivers to establish shared decision making and help identify expectations and goals of care.

Progress in our understanding SARS-CoV-2 and the development of therapeutics and practices to treat moderate-to-severe covid-19 have been impressive, driven by unprecedented collaboration, dedication, and hard work by patients, healthcare professionals, and clinician scientists around the globe. Developing treatments while sharing knowledge, data, and tools provides the promise of ending the current pandemic and preparing for the next global threat.

Competing interests: The BM/ has judged that there are no disqualifying financial ties to commercial companies. The authors declare the following other interests: JAL is supported by a contract in related work by the Agency for Healthcare Research and Quality (contract HHSP2332015000201 and grants R01HS028127 and R01HS026506) and the National Institute on Aging (grant P30AG059988). The BMJ policy on financial interests is here: https://www.bmj.com/sites/default/files/attachments/resources/2016/03/16-current-bmj-education-coi-form.pdf.

Provenance and peer review: Commissioned; not externally peer reviewed.

1 Yang W, Kandula S, Huynh M, etal. Estimating the infection-fatality risk of SARS-CoV-2 in New York City during the spring 2020 pandemic wave: a model-based analysis[Erratum in: Lancet Infect Dis. 2021 Jan;21] . Lancet Infect Dis 2021;21:203-12. doi: 10.1016/S1473-3099(20)30769-6 pmid. 33091374

2 Chen R, Liang W, Jiang M, etalMedical Treatment Expert Group for COVID-19. Risk factors of fatal outcome in hospitalized subjects with coronavirus disease 2019 from a nationwide analysis in China. Chest 2020;158:97-105. doi: 10.1016/.j.chest.2020.04.010 pmid: 32304772

3 Fried MW. Crawford IM, Mospan AR, etal. Patient characteristics and outcomes of 11,721 patients with covid19 hospitalized across the United States. Clin Infect Dis 2020:ciaa1268. doi: 10.1093/cid/ciaa1268 pmid: 32856034

4 Romano SD, Blackstock AJ, Taylor EV, etal. Trends in racial and ethnic disparities in covid-19 hospitalizations, by region-United States, March-December 2020. MMWR Morb Mortal Wkly Rep 2021;70:560-5. doi: 10.15585/mmwr.mm7015e2 pmid: 33857068

5 Thomas S, Patel D, Bittel B, etal. Effect of high-dose zinc and ascorbic acid supplementation vs usual care on symptom length and reduction among ambulatory patients with SARS-CoV-2 infection: the COVID A to Z Randomized Clinical Trial. JAMA Netw Open 2021;4:e210369. doi: 10.1001/jamanetworkopen.2021.0369 pmid: 33576820

6 Murai IH, Fernandes AL, Sales LP, etal. Effect of a single high dose of vitamin d3 on hospital length of stay in patients with moderate to severe covid-19: a randomized clinical trial. JAMA 2021;325:1053-60. doi: 10.1001/jama.2020.26848 pmid: 33595634

7 RECOVERY Collaborative Group Lopinavir-ritonavir in patients admitted to hospital with COVID-19 (RECOVERY): a randomised, controlled, open-label, platform trial. Lancet 2020;396:1345-52. doi: 10.1016/S0140-6736(20)32013-4

8 López-Medina E, López P, Hurtado IC, etal. Effect of ivermectin on time to resolution of symptoms among adults with mild covid-19: a randomized clinical trial. JAMA 2021;325:1426-35. doi: 10.1001/jama.2021.3071 pmid: 33662102

9 National Institutes of Health. NIH halts trial of COVID-19 convalescent plasma in emergency department patients with mild symptoms. 2021 Mar 2. https://www.nih.gov/news-events/newsreleases/nih-halts-trial-covid-19-convalescent-plasma-emergency-department-patients-mildsymptoms

10 Gottlieb RL, Nirula A, Chen P, etal. Effect of bamlanivimab as monotherapy or in combination with etesevimab on viral load in patients with mild to moderate covid-19: a randomized clinica trial. JAMA 2021;325:632-44. doi: 10.1001/jama.2021.0202 pmid: 33475701

11 Horby P, Lim WS, Emberson JR, etalRECOVERY Collaborative Group. Dexamethasone in hospitalized patients with covid-19. N Engl / Med 2021;384:693-704. doi: 10.1056/NEJMoa2021436 pmid: 32678530

12 Cano E), Fonseca Fuentes X, Corsini Campioli C, etal. Impact of corticosteroids in coronavirus disease 2019 outcomes: systematic review and meta-analysis. Chest 2021;159:1019-40. doi: 10.1016/j.chest.2020.10.054 pmid: 33129791

13 Sterne JAC, Murthy S, Diaz JV, etalWHO Rapid Evidence Appraisal for COVID-19 Therapies (REACT) Working Group. Association between administration of systemic corticosteroids and mortality among critically ill patients with covid-19: a meta-analysis. JAMA 2020;324:1330-41. doi: 10.1001/jama.2020.17023 pmid: 32876694
14 Beigel JH, Tomashek KM, Dodd LE, etalACTT-1 Study Group Members. Remdesivir for the treatment of covid-19-final report. N Engl J Med 2020;383:1813-26. doi: 10.1056/NEJMoa2007764 pmid: 32445440

15 Pan H, Peto R, Henao-Restrepo AM, etalWHO Solidarity Trial Consortium. Repurposed antiviral drugs for covid-19-interim WHO Solidarity trial results. N Engl J Med 2021;384:497-511. doi: 10.1056/NEJMoa2023184 pmid: 33264556

16 National Institutes of Health. Therapeutic management of adults with covid-19. Updated 11 Feb 2021. https://www.covid19treatmentguidelines.nih.gov/therapeutic-management/

17 Infectious Diseases Society of America. Remdesivir. Updated 9 Dec 2020. https://www.idsociety.org/covid-19-real-time-learning-network/therapeutics-and-interventions/remdesivir/

18 World Health Organization. COVID-19 clinical management: living guidance. 25 Jan 2021 https://apps.who.int/iris/handle/10665/338882

19 Rubin EJ, Longo DL, Baden LR. Interleukin-6 receptor inhibition in covid-19 - cooling the inflammatory soup. N Engl/J Med2021;384:1564-5. doi: 10.1056/NEJMe2103108 pmid: 33631064

20 RECOVERY Collaborative Group. Tocilizumab in patients admitted to hospital with COVID-19 (RECOVERY): preliminary results of a randomised, controlled, open-label, platform trial.medRxiv 2021. [Preprint.] doi: 10.1101/2021.02.11.21249258.

21 Kalil AC, Patterson TF, Mehta AK, etalACTT-2 Study Group Members. Baricitinib plus remdesivir for hospitalized adults with covid-19. N Engl / Med 2021;384:795-807. doi: 10.1056/NEJMoa2031994 pmid: 33306283

22 Vaughn VM, Gandhi T, Petty LA, etal. Empiric Antibacterial Therapy and Community-onset Bacterial Co-infection in Patients Hospitalized with COVID-19: A Multi-Hospital Cohort Study. Clin Infect Dis 2020:ciaa1239. doi: 10.1093/cid/ciaa1239 pmid: 32820807

23 Langford BJ, So M, Raybardhan S, etal. Bacterial co-infection and secondary infection in patients with COVID-19: a living rapid review and meta-analysis. Clin Microbiol Infect 2020;26:1622-9. doi: 10.1016/j.cmi.2020.07.016 pmid: 32711058

24 Infectious Diseases Society of America. Co-infection and antimicrobial stewardship. Updated 22 Jan 2021. https://www.idsociety.org/covid-19-real-time-learning-network/disease-manifestations-complications/co-infection-and-Antimicrobial-Stewardship/

25 Hu R, Han C, Pei S, Yin M, Chen X. Procalcitonin levels in COVID-19 patients. Int J Antimicrob Agents 2020;56:106051. doi: 10.1016/j.ijantimicag.2020.106051 pmid: 32534186

26 Nadkarni GN, Lala A, Bagiella E, etal. Anticoagulation, bleeding, mortality, and pathology in hospitalized patients with covid-19. J Am Coll Cardiol 2020;76:1815-26. doi: 10.1016/j.jacc.2020.08.041 pmid: 32860872

27 Rentsch CT, Beckman JA, Tomlinson L, etal. Early initiation of prophylactic anticoagulation for prevention of coronavirus disease 2019 mortality in patients admitted to hospital in the United States: cohort study. BMJ 2021;372:n311. doi: 10.1136/bmj.n311 pmid: 33574135

28 The REMAP-CAP ACTIV-4a, ATTACC Investigators. Therapeutic anticoagulation in critically ill patients with covid-19 - preliminary report.medRxiv 2021. [Preprint.] doi: 10.1101/2021.03.10.21252749.

29 Nguyen NT, Chinn J, Nahmias J, etal. Outcomes and mortality among adults hospitalized with covid-19 at US medical centers. JAMA Netw Open 2021:4:e210417. doi: 10.1001/jamanetworkopen.2021.0417 pmid: 33666657

30 Raoof S, Nava S, Carpati C, Hill NS. High-flow, noninvasive ventilation and awake (nonintubation) proning in patients with coronavirus disease 2019 with respiratory failure. Chest 2020;158:1992-2002. doi: 10.1016/j.chest.2020.07.013 pmid: 32681847

This article is made freely available for use in accordance with BMJ's website terms and conditions for the duration of the covid-19 pandemic or until otherwise determined by BMJ. You may use, download and print the article for any lawful, non-commercial purpose (including text and data mining) provided that all copyright notices and trade marks are retained. 